\title{
Role of cytokines in photodynamic therapy-induced local and systemic inflammation
}

\author{
SO Gollnick', SS Evans², H Baumann ${ }^{3}$, B Owczarczak', P Maier', L Vaughan', WC Wang', E Unger² \\ and BW Henderson*,I
}

'PDT Center, Roswell Park Cancer Institute, Elm and Carlton St, Buffalo, NY 14263, USA; ${ }^{2}$ Department of Immunology, Roswell Park Cancer Institute, Elm and Carlton St, Buffalo, NY 14263, USA; ${ }^{3}$ Department of Molecular and Cellular Biology, Roswell Park Cancer Institute, Elm and Carlton St, Buffalo, NY 14263, USA

Photodynamic therapy (PDT) of tumour results in the rapid induction of an inflammatory response that is considered important for the activation of antitumour immunity, but may be detrimental if excessive. The response is characterised by the infiltration of leucocytes, predominantly neutrophils, into the treated tumour. Several preclinical studies have suggested that suppression of longterm tumour growth following PDT using Photofrin ${ }^{\circledR}$ is dependent upon the presence of neutrophils. The inflammatory pathways leading to the PDT-induced neutrophil migration into the treated tumour are unknown. In the following study, we examined, in mice, the ability of PDT using the second-generation photosensitiser 2-[I-hexyloxyethyl]-2-devinyl pyropheophorbide-a (HPPH) to induce proinflammatory cytokines and chemokines, as well as adhesion molecules, known to be involved in neutrophil migration. We also examined the role that these mediators play in PDT-induced neutrophil migration. Our studies show that HPPH-PDT induced neutrophil migration into the treated tumour, which was associated with a transient, local increase in the expression of the chemokines macrophage inflammatory protein (MIP)-2 and KC. A similar increase was detected in functional expression of adhesion molecules, that is, E-selectin and intracellular adhesion molecule (ICAM)- I, and both local and systemic expression of interleukin (IL)6 was detected. The kinetics of neutrophil immigration mirrored those observed for the enhanced production of chemokines, IL-6 and adhesion molecules. Subsequent studies showed that PDT-induced neutrophil recruitment is dependent upon the presence of MIP-2 and E-selectin, but not on IL-6 or KC. These results demonstrate a PDT-induced inflammatory response similar to, but less severe than obtained with Photofrin ${ }^{\circledR}$ PDT. They also lay the mechanistic groundwork for further ongoing studies that attempt to optimise PDT through the modulation of the critical inflammatory mediators.

British Journal of Cancer (2003) 88, 1772 - 1779. doi:I0.1038/sj.bjc.6600864 www.bjcancer.com

(c) 2003 Cancer Research UK

Keywords: photodynamic therapy; inflammation; cytokines; chemokines; adhesion molecules

Photodynamic therapy (PDT) can efficiently and rapidly eradicate local tumours, leading to palliation of advanced disease or cure of early disease (Dougherty et al, 1998). The tumour response to PDT involves a complex interplay between direct cytotoxicity to the tumour cells and secondary damage to the tumour and adjacent tissue. In PDT employing the photosensitiser Photofrin ${ }^{\circledR}$, the combined effects on these tissue targets result in an intense inflammatory response and tumour involution within $24 \mathrm{~h}$. The inflammatory response is considered an important priming event for the development of specific antitumour immunity associated with Photofrin ${ }^{\circledR}$ PDT (Korbelik, 1996; Korbelik and Cecic, 1998; Dougherty et al, 1998). Photofrin ${ }^{\circledR}$-PDT-induced inflammatory changes are characterised by enhanced expression of a number of proinflammatory cytokines, including interleukin (IL)- $1 \beta$, tumour necrosis factor (TNF)- $\alpha$ and IL-6 (Evans et al, 1990; Nseyo et al, 1990; Kick et al, 1995; Gollnick et al, 1997). PDT-induced inflammation is accompanied by leucocyte infiltration into the treated tumour. A major fraction of the infiltrating cells are neutrophils,

*Correspondence: Dr BW Henderson;

E-mail: barbara.henderson@roswellpark.org

Received 19 August 2002; revised 17 January 2003; accepted 27 January 2003 but also included are mast cells and monocytes/macrophages (Korbelik et al, 1996; Gollnick et al, 1997). Experimental depletion of neutrophils through the use of anti-GR1 monoclonal antibodies $(\mathrm{mAb})$ diminishes the tumour response to Photofrin ${ }^{\mathbb{R}}$-PDT (de Vree et al, 1996a; Korbelik et al, 1996; Korbelik and Cecic, 1999). Based on these studies, it has become widely accepted that activated neutrophils in the treated tumour and their cellular functions are an important component in achieving long-term suppression of tumour growth following PDT. However, while the inflammatory response may be important to stimulate an adaptive antitumour response, excessive PDT-induced inflammation can cause severe adverse effects clinically (Dougherty, 2002).

The specific inflammatory pathways stimulated by PDT in tumour tissues in vivo have not been well defined. Recruitment of blood-borne neutrophils to sites of infection or tissue damage is tightly controlled by the locally produced proinflammatory cytokines and chemokines. Therefore, it is predicted that the same mechanisms are likely to be involved in PDT-induced inflammatory responses. TNF- $\alpha$, IL- $1 \beta$ and IL-6, produced by resident macrophages and stromal cells following stimulation, enhance the expression of vascular adhesion molecules including E-selectin and intracellular adhesion molecule (ICAM)-1 (Butcher and Picker, 1996; Di Carlo et al, 2002) as well as the synthesis of 
chemokines such as IL-8 (in humans, or macrophage inflammatory protein (MIP-2) in rodents) and Gro- $\alpha$ (in humans, or KC in rodents) (Mackay, 2001). These molecules collaboratively support the stepwise adhesion cascade required for neutrophil extravasation.

The effort to optimise PDT treatments has generated a number of new photosensitisers that are designed to overcome the problem of prolonged skin phototoxicity present with Photofrin ${ }^{\mathbb{R}}$. One of these, 2-[1-hexyloxyethyl]-2-devinyl pyropheophorbide-a (HPPH) (Bellnier et al, 1993), is a highly effective second-generation photosensitiser currently undergoing clinical testing. While this agent, upon light activation, provokes both direct tumour cell toxicity and vascular responses very similar to Photofrin ${ }^{\circledR}$ (Henderson et al, 1997), we have observed that the tumour response differs markedly from that following Photofrin ${ }^{\circledR}$-PDT. The inflammatory changes appear milder upon macroscopic observation and tumour involution occurs over a prolonged period of $48-96 \mathrm{~h}$ as opposed to acute effects of Photofrin ${ }^{\mathrm{B}}$-PDT that occur within hours. Keeping in mind the balance between an inflammatory response sufficient to activate antitumour immunity on the one hand, and an excessive response that raises the danger of adverse effects, we decided to examine the inflammatory response evoked by tumour treatment with the new photosensitiser HPPH. This work represents the first detailed mechanistic analysis of the involvement of proinflammatory cytokines, chemokines and adhesion molecules in the inflammatory response to PDT.

\section{MATERIAL AND METHODS}

\section{Animals and tumour system}

Pathogen-free BALB/cJ and C. 129S2(B6)-Cmkar2 ${ }^{\text {tm1Mwm }}$ (CXCR2 KO) mice were obtained from the Jackson Laboratories (Bar Harbor, ME, USA) and were used for all experiments. Animals were housed in microisolator cages in a laminar flow unit under ambient light. Six to 12 -week-old animals were inoculated intradermally on the shoulder with $2 \times 10^{5}$ EMT6 mammary tumour cells (Henderson et al, 1985) harvested from exponentially growing cultures. While the EMT6 cell line is highly antigenic and significantly immunogenic (Kurt et al, 1995), no spontaneous tumour regressions were observed in this study. Prior to tumour inoculation and/or light treatment, all hair was removed from the prospective treatment site by shaving and depilation. Tumours were used for experimentation about 10 days after inoculation when they had reached a size of $6-8 \mathrm{~mm}$ in diameter. All animal experimentation was carried out following ethical committee approval and meet the standards required by the UKCCCR guidelines (Workman et al, 1998).

\section{Reagents}

Clinical-grade, pyrogen-free HPPH was obtained from the Roswell Park Pharmacy and reconstituted to $0.4 \mathrm{~mm}$ in pyrogen-free $5 \%$ dextrose (D5W; Baxter Corp., Deerfield, IL, USA) containing 2\% ethanol and $0.1 \%$ Tween. Antibodies against murine $\mathrm{KC}$ (rat $I G_{2 \mathrm{a}}$ ), MIP-1 (rat IgG $\mathrm{Ig}_{2 \mathrm{~b}}$ ), MIP-2 (rat IgG $\mathrm{Ig}_{2 \mathrm{~b}}$ ) and IL-6 (goat polyclonal IgG) were purchased from R\&D Systems (Minneapolis, MN, USA). Rat IgG and goat IgG were obtained from Caltag (San Francisco, CA, USA) and used as isotype controls. Antimurine E-selectin (CD62E) mAb (10E9.6, rat $\left.\operatorname{IgG}_{2 \mathrm{a}} \kappa\right)$, antimurine ICAM-1 (CD54) $\mathrm{mAb}\left(3 \mathrm{E} 2\right.$, Armenian hamster $\left.\operatorname{IgG}_{1} \kappa\right)$ and RITC-labelled murine antihamster IgG (G70-204, G94-90.5) were purchased from BD Pharmingen (San Diego, CA, USA). Antimurine PECAM-1 (CD31) mAb (390, rat $\operatorname{IgG}_{2 \mathrm{a}} \kappa$ ) was from Beckman Coulter (Miami, FL, USA). Goat anti-rat IgG-FITC, rat serum and hamster sera were from Sigma, Inc. (Saint Louis, MO, USA). Goat serum was a gift from Dr Richard Bankert (State University of New York at Buffalo, Buffalo, NY, USA) and mouse serum was from Dr Yasmin Thanavala (Roswell Park Cancer Institute, Buffalo, NY, USA).

\section{In vivo $\mathrm{PDT}$ treatment}

Animals were given intravenous injections via tail vein of $0.6 \mu \mathrm{mol} \mathrm{kg}{ }^{-1} \mathrm{HPPH}$, followed $24 \mathrm{~h}$ later with illumination at $665 \mathrm{~nm}$ light using an argon-dye laser system (Spectra Physics, Mt View, CA, USA). A treatment field $1 \mathrm{~cm}$ in diameter, containing the tumour, was illuminated at $75 \mathrm{~mW} \mathrm{~cm}^{-2}$ for a total light dose of $100-135 \mathrm{~J} \mathrm{~cm}^{-2}$. In some experiments, a single tumour was treated on animals bearing tumours on both shoulders; the untreated or contralateral tumour was used as a 'drug only' control. Following PDT, animals were either observed for tumour regrowth, or were killed and tumours were harvested at selected time intervals following light exposure for cell and protein analysis, and immunohistochemistry. In some experiments, animals were bled by tail-end clipping when consecutive daily blood samplings were needed or via heart puncture at the end of experiments. Serum from these blood samples were subjected to immunoelectrophoretic quantification of haptoglobin (HP) (Baumann, 1988) or ELISA. All experiments included control untreated animals and treated animals with photosensitiser only. All animal experimentation was carried out following ethical committee approval and meet the standards required by the UKCCCR guidelines (Workman et al, 1998).

\section{ELISA}

Tumour tissues were processed immediately after harvest as described (Gollnick et al, 1997). Total protein was determined by the Bio-Rad protein assay (Bio-Rad Lab., Hercules, CA, USA). KC, MIP-1, MIP-2 and IL-6 protein levels in control and treated tumours, and/or serum were determined by ELISA. ELISA kits specific for each protein were purchased from R\&D Systems and used according to the manufacturer's suggestion. The assays were performed in triplicate on samples isolated from three animals.

\section{Flow cytometry}

The cell populations present in EMT6 tumours before and after PDT were characterised through FACS analysis, using panels of mAbs to detect specific cell surface antigens as described previously (Gollnick et al, 1997). mAbs conjugated directly with fluorescein or phycoerythrin or biotin were used to quantify cells expressing the common leucocyte antigen CD45 (GIBCO/BRL), CD4 and CD8 T-cell antigens (PharMingen, San Diego, CA, USA), CD11b (PharMingen), IA ${ }^{\mathrm{d}}$ (PharMingen) and Gr-1 (PharMingen). Appropriate immunoglobulin isotypes were used as controls. In cases where biotinylated antibodies were used, streptavidincychrome (PharMingen) was added as a detection reagent.

For flow cytometric analysis, a two-laser FACStar Plus (BectonDickinson, San Jose, CA, USA) flow cytometer was used, operating in the ultraviolet (UV) and at $488 \mathrm{~nm}$. Four colours and light scattering properties could be resolved employing 420/20, 530/30 and 575/30 band-pass filters and a 640 long-pass filter. Data were acquired from 5000 cells, stored in collateral list mode, and analysed using the WinList processing program (Verity Software House, Inc., Topsham, ME, USA). Results are presented as the average percentage of total cells; a total of three animals were analysed for each treatment group.

\section{Immunofluorescence analysis of vascular adhesion molecules}

EMT6 murine mammary tumours were snap frozen in Tissue Tek (Sakura, Torrance, CA, USA) and $9 \mu \mathrm{m}$ cryostat sections were fixed 
for $10 \mathrm{~min}$ using a $3: 1 \mathrm{methanol/acetone} \mathrm{solution.} \mathrm{For} \mathrm{immuno-}$ fluorescence staining, tissue sections were sequentially washed in $0.02 \%$ PBS azide and $0.1 \%$ PBS Triton X-100 before blocking with $10 \%$ goat serum or $10 \%$ mouse serum diluted in a $1 \%$ fetal bovine serum/RPMI 1640 solution (GIBCO BRL, Grand Island, NY, USA) for $10 \mathrm{~min}$. The sections were then incubated for $1 \mathrm{~h}$ with $\mathrm{mAbs}$ specific for murine E-selectin, ICAM-1 or PECAM-1. As controls, sections were incubated with either rat sera or hamster sera (Sigma, Inc., Saint Louis, MO, USA). The sections were washed for $1 \mathrm{~h}$ in $0.02 \%$ PBS azide and then incubated with either FITC or RITC-labelled secondary Ab for $1 \mathrm{~h}$. The sections were then washed overnight in $0.02 \%$ PBS azide and mounted using Aqua Poly/ Mount (Polysciences, Inc., Warrington, PA, USA). Images were recorded using an Olympus BX50 upright microscope equipped with a SPOT RT camera (Spectra Services, Webster, NY, USA) with equivalent exposure times and image settings.

\section{Neutrophil isolation and frozen-section adhesion assay}

Human peripheral blood neutrophils were isolated from normal donor buffy-coat leucocyte concentrates (American Red Cross, Rochester NY, USA) by Ficoll - Hypaque centrifugation and 3\% dextran/0.9\% saline-sedimentation as described (Anderson et al, 1981; Smith et al, 1989). Following hypotonic lysis of red blood cells (RBC) in $0.2 \%$ saline, isolated neutrophils ( $>99 \%$ pure) were suspended at $5 \times 10^{7} \mathrm{ml}^{-1}$ in $1 \%$ fetal calf serum (FCS)/RPMI 1640 (GIBCO BRL) and used immediately in adhesion assays.

Adhesion of isolated neutrophils to tumour microvessels in frozen-tissue sections was assessed in vitro under mechanical shear as described (Lewinsohn et al, 1987; Evans et al, 2001). Briefly, a total of $5 \times 10^{6}$ neutrophils in $100 \mu \mathrm{l}$ of FCS/RPMI 1640 medium were overlaid onto $12 \mu \mathrm{m}$ cryosections of tumour tissues from PDT-treated or nontreated mice. Selected tumour tissue specimens were pretreated with function-blocking mAb specific for E-selectin $\left(10 \mu \mathrm{g} \mathrm{ml}^{-1}\right.$; BD Pharmingen, San Diego, CA, USA) or isotype-matched negative control antibodies. The assay was performed at $4{ }^{\circ} \mathrm{C}$ for $30 \mathrm{~min}$ with mechanical rotation (112 r.p.m.; Labline Instrument, Labline Instrument, Inc., Melrose Park, IL, USA). After removal of nonadherent cells, sections were fixed in $3 \%$ glutaraldehyde, and stained with $0.5 \%$ toluidine/absolute ethanol. Neutrophil adhesion was quantified by light microscopy in a total of 100 microvessels per tumour tissue specimen; data are the mean \pm s.e. of triplicate specimens.

\section{Antibody treatments}

For chemokine, cytokine and adhesion molecule neutralisation studies, anti-KC, anti-MIP-2, anti-IL-6, anti-E-selectin or isotypematched control antibodies were administered immediately following $\left(100 \mu \mathrm{g}_{\text {mouse }}{ }^{-1}\right.$; i.v.) PDT treatment or 24 and $48 \mathrm{~h}$ $\left(50 \mu\right.$ mouse $^{-1}$; i.v.) post-PDT treatment. Neutrophil depletion was accomplished using anti-GR-1 antibodies $\left(100 \mu \mathrm{g} \mathrm{mouse}^{-1}\right.$; i.v.) administered $24 \mathrm{~h}$ prior to PDT, immediately and $24 \mathrm{~h}$ postPDT. Tumour growth was monitored as above.

\section{Statistical analysis}

Statistical analysis was performed using a nonpaired Student's $t$-test. Statistical analysis of survival data was performed by logrank test. In all cases, significance was defined as $P<0.05$.

\section{RESULTS AND DISCUSSION}

\section{HPPH-PDT increases the proportion of neutrophils in EMT6 tumours}

We and others have previously shown that the local inflammatory response following PDT with Photofrin ${ }^{\mathbb{R}}$ is characterised by a

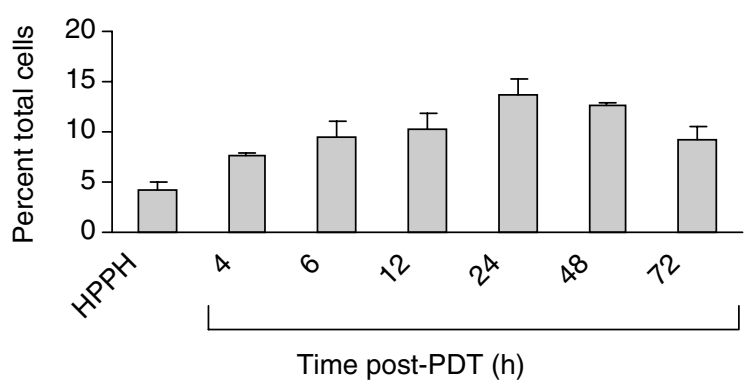

Figure I HPPH-PDT enhances neutrophil infiltration into the treated tumour. Animals were treated with $0.6 \mu \mathrm{mol} \mathrm{kg}{ }^{-1} \mathrm{HPPH}$, followed $24 \mathrm{~h}$ later by $100 \mathrm{~J} \mathrm{~cm}^{-2}$ of $665 \mathrm{~nm}$ light. Tumours were harvested at various times post-PDT and the infiltrating cell populations were analysed by flow cytometry as described in Materials and Methods. Samples were collected from control animals (no treatment, HPPH alone) at $6 \mathrm{~h}$ 'post-PDT'. Results are reported as the percentage of total cells present in the tumour that are $\mathrm{CD}_{4} 5^{+}$and $\mathrm{Gr}-\mathrm{I}^{+}$. A minimum of three mice were analysed at each time point. Error bars represent the s.e.

strong, time-dependent infiltration of neutrophils into the treated tumour (Korbelik et al, 1996; Gollnick et al, 1997; Sun et al, 2002). To determine whether HPPH-PDT also resulted in inflammatory cell infiltration, tumour-infiltrating host cell numbers and phenotype were analysed by flow cytometry. Two phenotypes were predominant among CD45 $5^{+}$host cells, neutrophils $\left(\mathrm{CD} 11^{+}\right.$ $\left.\mathrm{GR} 1^{\mathrm{hi}}\right)$ and macrophages $\left(\mathrm{CD} 11^{+} \mathrm{GR} 1^{\mathrm{lo}}\right)$. HPPH-PDT, at a dose that achieved long-term tumour suppression in $\sim 50 \%$ of animals, resulted in a modest, time-dependent increase in the percentage of neutrophils in the treated tumour (Figure 1). Within $4 \mathrm{~h}$ of treatment, the percentage of neutrophils was significantly increased $(P<0.007$ as compared to HPPH treatment in the absence of light). The proportion of neutrophils continued to increase and remained elevated for at least $72 \mathrm{~h}$ post-treatment. The differences in neutrophil levels over the period of $6,12,24$ and $48-72 \mathrm{~h}$ postillumination were not significant $(P>0.41)$. Moreover, the increase was no more than three-fold over controls and rarely exceeded $20 \%$ of total cells during the period of observation. The percentage of macrophages $(9.3 \%)$ did not change significantly throughout the observation period. The level of lymphocytes did not exceed $5 \%$ of total cells and that also did not change significantly after HPPH-PDT (data not shown).

Thus, like Photofrin ${ }^{\mathbb{R}}$-PDT, HPPH-PDT results in an influx of neutrophils into the treated tumour. The kinetics of neutrophil migration observed were similar to those seen following Photofrin ${ }^{\mathbb{R}}$-PDT (Gollnick et al, 1997), although the number of infiltrating neutrophils was considerably less following $\mathrm{HPPH}-$ PDT $\left(37 \%\right.$ of the total cells $24 \mathrm{~h}$ following Photofrin ${ }^{\mathbb{R}}$-PDT $v s$ $13.8 \%$ of the total cells $24 \mathrm{~h}$ following HPPH-PDT). These results are consistent with the lower degree of inflammation seen following HPPH-PDT as compared to Photofrin ${ }^{\circledR}$-PDT (Bellnier et al, 1993) and may be a reflection of the kinetics of tumour destruction. Photofrin ${ }^{\mathbb{R}}$-PDT-treated tumours have regressed within the first $24-48 \mathrm{~h}$ of treatment, while HPPH-PDT-treated tumours are not eliminated for $48-72 \mathrm{~h}$.

\section{HPPH-PDT enhances expression of neutrophil attractant chemokines in EMT6 tumours}

Leucocyte migration is a tightly controlled process that is regulated by chemokines/cytokines and mediated by adhesion molecules. Murine neutrophil migration is regulated in large part by the chemokines MIP-2 and KC. KC is constitutively expressed and is believed to be involved in basal neutrophil migration (Bozic et al, 1995). In contrast, MIP-2 is inducible and thought to mediate 
stress- or injury-induced neutrophil migration (Biedermann et al, 2000 ). Also involved in neutrophilic inflammation is MIP-1 $(\alpha$ and $\beta)$, which can activate granulocytes, stimulate the production of reactive oxygen species in neutrophils and induce the generation of proinflammatory cytokines IL-1, IL-6 and TNF (Adams and Lloyd, 1997).

Expression of MIP-2 and KC in HPPH-PDT-treated tumours was significantly elevated by $4 \mathrm{~h}$ post-treatment $(P<0.009$ as compared to HPPH controls) and remained elevated for up to $24 \mathrm{~h}$ posttreatment. Although the protein levels of $\mathrm{KC}$ present in the tumour were higher than those for MIP-2 (Figure 2A), the fold induction for MIP-2 was significantly higher $(P<0.01)$ than that for KC (Figure 2B). The induction of MIP-2 protein by PDT corresponded to a $27.1 \pm 4.9$-fold induction at $6 \mathrm{~h}$ post-treatment as compared to HPPH controls $(P<0.0004)$, while the increase in $\mathrm{KC}$ corresponded to an $11.2 \pm 1.2$-fold induction at $6 \mathrm{~h}$ postPDT $(P<0.0001$ when compared to HPPH alone controls). The levels of KC and MIP-2 were unchanged in untreated contralateral tumours as compared to chemokine levels in treated tumours, indicating that the induction of MIP-2 and KC was not the result of a systemic mediator. Thus, HPPH-PDT induced a timedependent, local increase in two neutrophil attractant chemokines, MIP-2 and KC. The kinetics of expression paralleled that of neutrophil infiltration. We also observed a trend towards increased levels of MIP- $1 \alpha$ in treated tumours at 24 and $48 \mathrm{~h}$ post-treatment (data not shown), but the changes were not significant $(P<0.167)$.
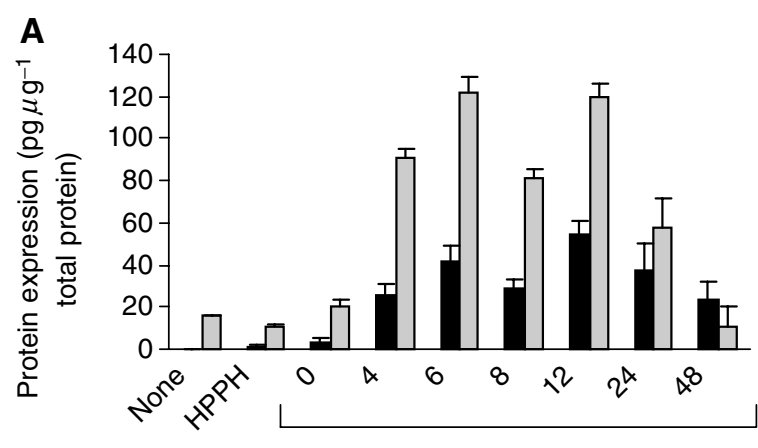

Time post-PDT (h)

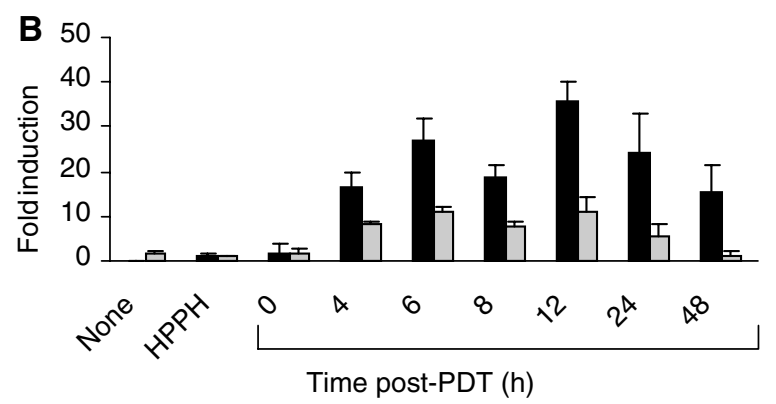

Figure 2 Induction of MIP-2 and KC following PDT. Animals were treated with PDT as described in Figure I. Tumours and sera were collected from treated animals at various times post-PDT. Tumours and sera were collected from control animals (no treatment, HPPH alone) at $6 \mathrm{~h}$ 'post-PDT'. The total amount of protein per sample was determined using the Bio-Rad protein assay. KC and MIP-2 levels were determined by ELISA and are reported as (A) $p g \mu \mathrm{g}^{-1}$ of total protein or (B) fold induction where chemokine expression is reported in relation to the expression found in tumours treated with $\mathrm{HPPH}$ alone. A minimum of three mice were analysed at each time point. Error bars represent the s.e. MIP-2

\section{HPPH-PDT induces local and systemic expression of IL-6}

We have previously shown that Photofrin ${ }^{\circledR}$-PDT stimulates the expression of IL-6 in the tumour (Gollnick et al, 1997). IL-6 is characterised as a proinflammatory cytokine primarily because of its role in release of acute-phase proteins (Baumann and Gauldie, 1994; Suffredini et al, 1999) and complement activation (Knittel et al, 1997; Minta et al, 2000; Schieferdecker et al, 2000). In some reports, IL-6 has also been implicated in neutrophil migration (Dalrymple et al, 1995; Romano et al, 1997; Hurst et al, 2001; Suwa et al, 2001) and has been shown to contribute to the rise in circulating neutrophils observed following Photofrin-PDT (Cecic and Korbelik, 2002). Figure 3A shows that HPPH-PDT strongly enhanced the expression of IL- 6 in the tumour. IL- 6 levels rose sharply up to $6 \mathrm{~h}$ after treatment $(P<0.0001$ as compared to HPPH treatment alone) and remained significantly elevated during the $48 \mathrm{~h}$ post-treatment period $(P<0.0003)$. HPPH-PDT also induced a significant increase in circulating levels of IL-6 (Figure 3A), which became evident within $4 \mathrm{~h}$ post-treatment $(P<0.0008$ when compared to HPPH only controls). The levels remained significantly elevated up to $24 \mathrm{~h}$ post-treatment $(P<0.018$ as compared to HPPH alone controls). The kinetics of local IL-6 induction reached maximal levels by $6 \mathrm{~h}$ post-treatment, which is analogous to the kinetics observed for the chemokines, MIP-2 and KC, as well as for
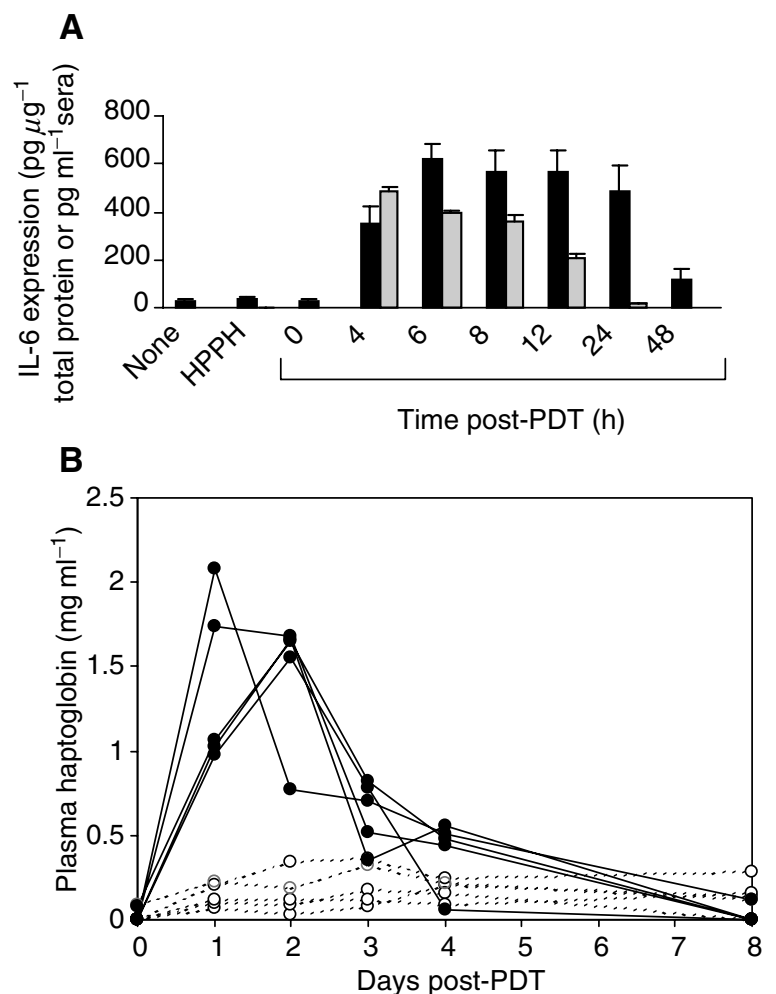

Figure 3 Induction of local and systemic IL-6 by PDT. Samples were collected from control animals (no treatment, $\mathrm{HPPH}$ alone) at $6 \mathrm{~h}$ 'postPDT'. The total amount of protein per tumour was determined using the Bio-Rad protein assay. (A) IL-6 levels were determined by ELISA and are reported as either $\mathrm{pg} \mu \mathrm{g}^{-1}$ of total protein (tumour) or $\mathrm{pg} \mathrm{ml}^{-1}$ serum. A minimum of three mice were analysed at each time point. Error bars represent the s.e. Tumour IL-6 tumour-bearing mice were subjected to HPPH treatment. At $0 \mathrm{~h}$, one group of five mice was exposed to light $\left(135 \mathrm{~J} \mathrm{~cm}^{-2}\right.$ ) (filled symbols), and another group of five mice was kept in the dark (control, open symbols). Every $24 \mathrm{~h}$, a blood sample was collected for each mouse and the serum level of HP was determined by immunoelectrophoresis. The values were calculated in $\mathrm{mg} \mathrm{ml}^{-1}$ and the HP concentration for each mouse and bleeding was reproduced. 
neutrophil migration. Similar kinetics of IL-6 expression were also observed following Photofrin ${ }^{\circledR}$-PDT (Gollnick et al, 1997).
The bioactivity of the systemic IL- 6 was determined by the level of haptoglobin (HP) in the sera of control (HPPH only) and HPPH-PDT-treated animals over an 8 day post-PDT treatment

Table I Immunofluorescence staining patterns of adhesion molecules on EMT6 microvessels following PDT

Time after PDT (h)

\begin{tabular}{|c|c|c|c|c|c|c|c|c|c|c|c|}
\hline Adhesion molecule & None & HPPH & 0 & I & 3 & 6 (PDT) & $6(\text { Untx) })^{a}$ & 8 & 12 & 24 & 48 \\
\hline $\begin{array}{l}\text { E-selectin (CD62E) } \\
\text { ICAM-I (CD54) } \\
\text { PECAM-I CD3 I }\end{array}$ & $\begin{array}{l}-{ }^{\mathrm{b}} \\
-/ \pm \\
+++\end{array}$ & $\begin{array}{l}- \\
-/ \pm \\
+++\end{array}$ & $\begin{array}{l}-1 \pm \\
-1+ \\
+++\end{array}$ & $\begin{array}{l}-/ \pm \\
-1+ \\
+++\end{array}$ & $\begin{array}{l}-1+ \\
-1++ \\
+++\end{array}$ & $\begin{array}{l}-1+++ \\
-1 \pm \\
++++\end{array}$ & $\begin{array}{l}- \\
-1++ \\
+++\end{array}$ & $\begin{array}{l}-1+ \\
-1++ \\
++\end{array}$ & $\begin{array}{l}-1 \pm \\
-1+ \\
-1++\end{array}$ & $\begin{array}{l}-1 \pm \\
-1+ \\
N D^{c}\end{array}$ & $\begin{array}{l}- \\
-/ \pm \\
\mathrm{ND}\end{array}$ \\
\hline
\end{tabular}

${ }^{a}$ Untx refers to the contralateral tumour that was not treated with light in animals receiving HPPH and having one tumour treated with light. ${ }^{\mathrm{b}} \mathrm{Staining}$ intensity of tumour microvessels ranges from undetectable $(-)$ to very high levels $(++++) .{ }^{c} N D$, not determined.

A

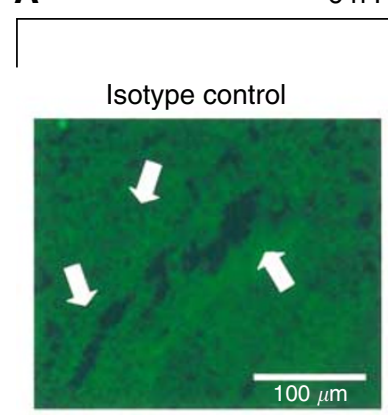

Isotype control

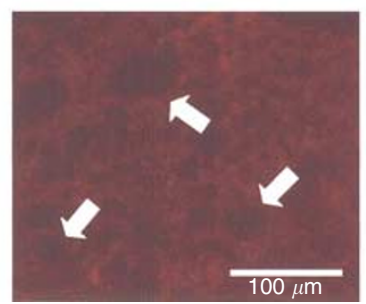

E-selectin

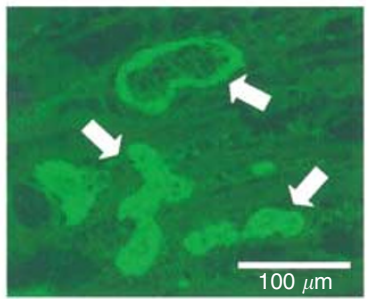

ICAM-1

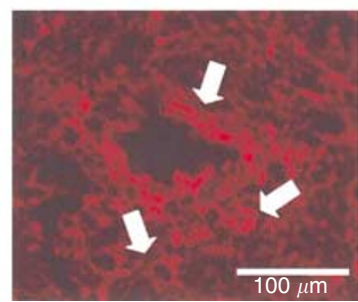

$6 \mathrm{~h} \mathrm{HPPH}+$ no PDT

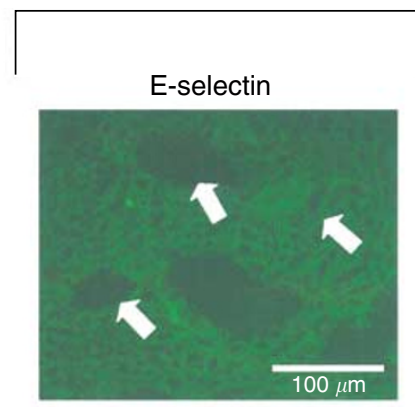

ICAM-1

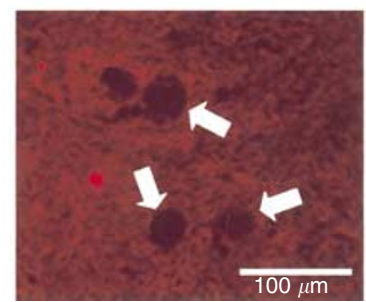

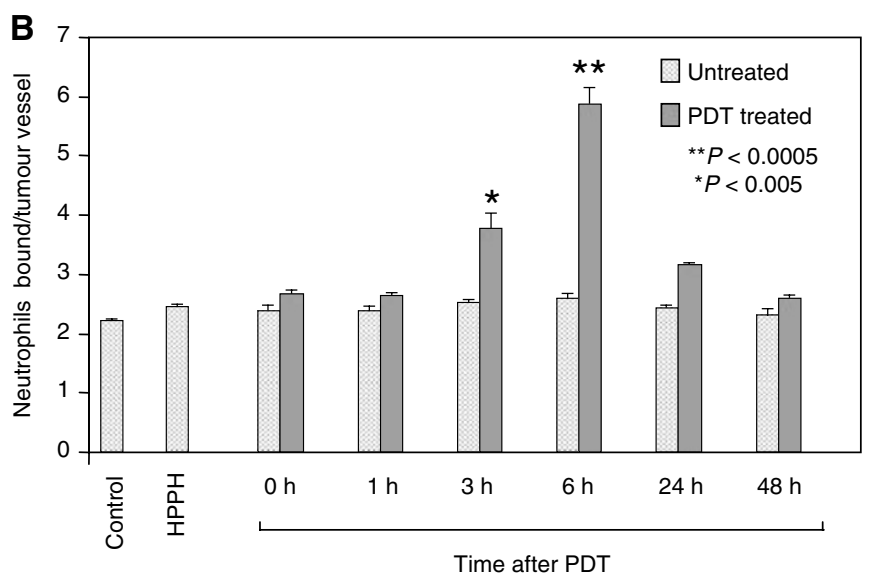

Figure 4 HPPH-PDT enhances adhesion molecule expression and neutrophil adhesion in tumour microvessels. Animals were treated as in Figure I for the indicated time periods and tumour cryosections were either stained for vascular adhesion molecule expression using specific mAb (A) or evaluated for the ability to support adhesion of neutrophils under mechanical shear $(\mathbf{B})$. In $(\mathbf{A})$, arrows denote tumour vessels; note that fluorescence was not detected in tumour vessels stained with isotype-matched control Ab (left panels) or in tumours that were not treated with light (i.e. no PDT, right panels). In contrast, Eselectin and ICAM-I were highly expressed on tumour vessels following HPPH-PDT treatment. Data in (B) are the mean +s.d. of triplicate samples and are representative of three independent experiments. The differences between adhesion in untreated contralateral tumours and PDT-treated tumours were significant, $P<0.005(*), P<0.0005\left(^{* *}\right)$ by unpaired two-tailed Student's $t$-test. 
period (Figure 3B). HP is a member of the type 2 acute-phase proteins and the transcriptional activation of the $\mathrm{Hp}$ gene in liver is dependent upon IL-6 (Baumann et al, 1989). The relative change in expression of this acute-phase protein is proportional to the level of inflammation (Baumann and Gauldie, 1994). The sera of animals treated with HPPH-PDT reached peak values of $2 \mathrm{mg} \mathrm{ml}^{-1}$ of serum $24-48 \mathrm{~h}$ post-PDT. The HP concentration returned to pretreatment levels after 8 days post-treatment period. In contrast, the sera of control animals, which received HPPH but were not exposed to light, maintained an HP level of $<0.3 \mathrm{mg} \mathrm{ml}^{-1}$ over the course of the experiment. The time course and relative change in circulating HP was characteristic for an acute-phase reaction observed after severe forms of tissue injury, and that involved the mediator function of IL-6 (Kopf et al, 1994).

\section{HPPH-PDT enhances the expression of ICAM and E-selectin in EMT6 microvessels}

In addition to a dependence on chemokines, expression of vascular endothelial adhesion molecules is also required for neutrophil migration. The effect of HPPH-PDT on the expression of E-selectin and ICAM-1 was examined by immunofluorescence analysis (Figure 4A) and the results are summarised in Table 1. HPPHPDT resulted in a transient time-dependent increase in E-selectin and ICAM-1 expression on the tumour microvessels that peaked at $6 \mathrm{~h}$ post-treatment and returned to baseline by $48 \mathrm{~h}$ post-treatment. PDT-induced expression of E-selectin and ICAM-1 was dependent on the presence of light as adhesion molecule expression did not increase in the untreated contra-lateral tumour. This finding also indicates that circulating cytokines were not effective in eliciting the change in adhesion molecules, but depended on locally produced regulatory factors. The induction of E-selectin and ICAM-1 was heterogeneous, ranging in staining intensity from to ++ at the $6 \mathrm{~h}$ point for example (Table 1). In this regard, some vessels within the tumour showed a marked increase in vascular display of E-selectin while other vessels in close proximity failed to respond (Figure 4A). The increase in E-selectin was restricted to the tumour microvasculature. In contrast, the increase in ICAM-1 immunofluorescent staining was more diffuse, reflecting of enhanced expression on both vascular endothelium and infiltrating cells. Negative control staining with isotype-matched rat IgG or hamster IgG confirmed that E-selectin and ICAM-1staining was specific. The sections were also stained with PECAM-1 (CD31) as a control. PECAM-1 staining was unaffected by PDT at the earlier time points (up to $6 \mathrm{~h}$ ); however, the staining intensity began to diminish at $8 \mathrm{~h}$ post-treatment. This decrease likely reflects a loss in vessel integrity rather than a loss of PECAM-1 expression (BWH and SE, unpublished observations). Like the enhanced expression of chemokines and IL-6, the kinetics of adhesion molecule expression mirrors those of neutrophil influx.

\section{HPPH-PDT stimulates adhesion of neutrophils to EMT6 microvessels}

The effect of PDT on the function of adhesion molecules was monitored by determining the ability of neutrophils to adhere to EMT6 microvessels in frozen-tissue sections under mechanical shear following in vivo PDT treatment. As can be seen in Figure 4B, PDT significantly enhanced neutrophil/endothelial adhesion in a time- and light-dependent manner (drug alone $v s \quad 6 \mathrm{~h}$ posttreatment: $P<0.0005)$ with kinetics similar to those observed for induction of adhesion molecule and chemokine expression. The enhanced adhesion was restricted to tumours that had been treated with PDT. No increases in neutrophil adhesion were observed in contralateral tumours, which did not receive light, on the same animal, implicating again a local rather than systemic mechanism.

\section{HPPH-PDT enhanced neutrophil migration is dependent} upon E-selectin and MIP-2

The similarity in kinetics, as well as previous findings (Biedermann et al, 2000), led us to postulate that a causal relation may exist between the induction of chemokine/cytokine, functional adhesion molecule expression and neutrophil migration. This hypothesis was confirmed by blocking and depletion studies. HPPH-PDTenhanced neutrophil adhesion was dependent upon E-selectin as blocking antibodies to E-selectin eliminated the adhesion of neutrophils to EMT6 microvessels $(P<0.0003$; Figure 5A). Adhesion was not abrogated in the presence of an isotype-matched control antibody. Thus, the characteristic neutrophil infiltration associated with PDT is due, at least in part, to an induction of

A

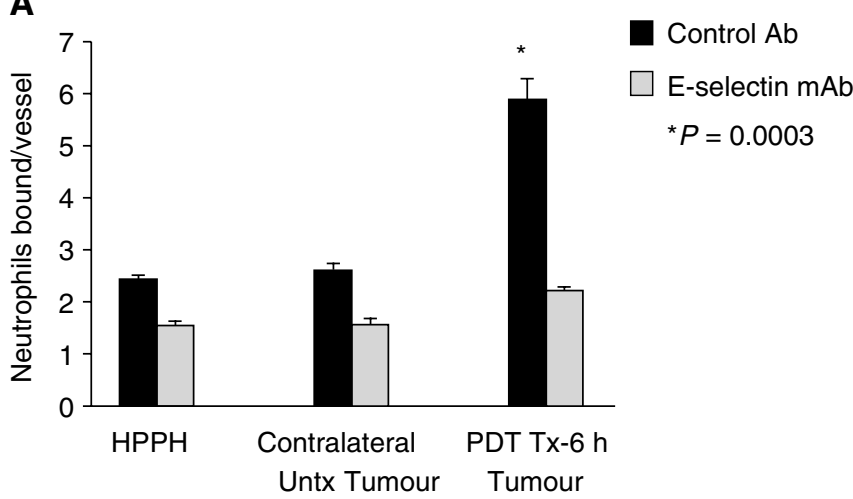

B

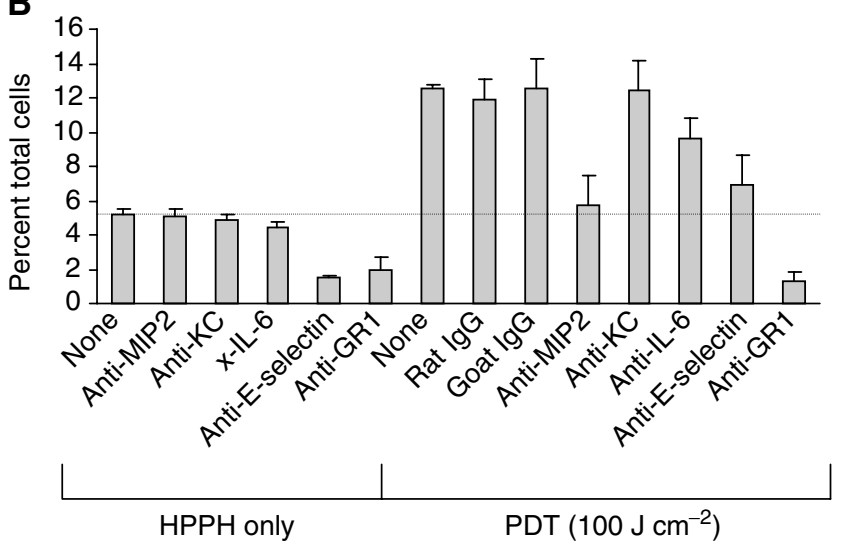

Figure 5 (A) HPPH-PDT stimulates E-selectin-dependent adhesion of neutrophils to tumour microvessels. Animals were treated with HPPH for $6 \mathrm{~h}$ and separated into two groups: (I) the drug only group did not receive PDT treatment and (2) in the second group, tumours were treated with PDT, while contralateral tumours were not treated with light. Neutrophil adhesion to tumour microvessels was evaluated under mechanical shear in tumour cryosections in the presence of isotype-matched negative control $\mathrm{Ab}$ or function-blocking $\mathrm{mAb}$ specific for E-selectin $\left(\left.10 \mu \mathrm{g} \mathrm{ml}\right|^{-1}\right)$. Data are the mean \pm s.d. of triplicate samples and are representative of three independent experiments. The difference between adhesion in untreated contralateral tumours and PDT-treated tumours was significant, $P<$ $0.00035\left(^{*}\right)$ by unpaired two-tailed Student's t-test. (B) Inhibition of MIP-2 and E-Selectin expression following PDT diminishes PDT-induced neutrophil infiltration into EMT6 tumours. Tumour-bearing animals were treated with PDT as described under Figure I. Anti-MIP-2, anti-E-selectin, anti-IL-6, anti-GR-I, rat IgG (isotype control for anti-MIP-2 and anti-Eselectin) or goat IgG (isotype control for anti-IL-6 and anti-GR-I) were administered immediately after PDT. Tumours were isolated $24 \mathrm{~h}$ postPDT and the infiltrating cell populations were determined by flow cytometry. The dashed line indicates the level of neutrophils found in control tumours. Mean values from three animals of the percentage of total cells that are $\mathrm{CD} 45^{+}$and GR- $\mathrm{I}^{+}$are shown. Error bars represent the s.e.m. 
E-selectin. Other studies have shown that PDT-induced adherence of neutrophils to endothelial cells in vitro (de Vree et al, 1996b) and in vivo (Dellian et al, 1995; Adili et al, 1996; Sluiter et al, 1996; Rousset et al, 1999) also involved $\beta_{2}$-integrins (LFA-1) (Sluiter et al, 1996; de Vree et al, 1996b).

Blocking E-selectin and MIP-2 action through the use of neutralising antibodies, administered immediately after completion of PDT treatment, led to a significant reduction in neutrophil accumulation to almost baseline levels by $6 \mathrm{~h}$ post-treatment (PDT+anti-MIP-2 vs PDT+rat IgG: $P<0.0024$; PDT+anti-E-selectin vs PDT+rat IgG: $P<0.04$ ) (Figure 5B). This confirms the importance of E-selectin in PDT-induced neutrophil migration, and implies that the increased level of neutrophils in the tumour was the result of recruitment via MIP-2. Administration of antiGR-1 antibodies also reduced neutrophil levels in both treated and control tumours to levels below those found in when anti-MIP-2 was used (Figure 5B; PDT+anti-GR-1 vs PDT+rat IgG: $P<0.0095$ ). No significant neutrophil reduction was achieved with anti-KC antibodies.

Although IL-6 was shown to affect induction of systemic neutrophilia by Photofrin-PDT (Cecic and Korbelik, 2002; Sun et al, 2002), neutralisation of IL-6 did not significantly affect the levels of neutrophils infiltrating the tumour post-PDT (Figure $5 \mathrm{~B}$; PDT+anti-IL-6 vs PDT+goat IgG: $P<0.533)$. Moreover, neutralisation of IL-6 did not block induction of E-selectin or ICAM-1 on tumour microvessels or appear to play a role in long-term control of EMT6 tumours by HPPH-PDT (data not shown). Similar results were recently reported by Sun et al (2002). In this study, neutralising antibodies to IL-6 were administered intraperitoneally 30 min prior to mTHPC-PDT of s.c. SCCVII tumours. No effect on long-term tumour response was observed. These results suggest that the role of IL- 6 in PDT-induced inflammation may vary depending on the photosensitiser used and the tumour type studied.

The role of MIP-2 in PDT-induced neutrophil migration was confirmed by examining neutrophil migration in mice deficient for CXCR2, the receptor for both MIP-2 and KC (Rollins, 1997), following HPPH-PDT. EMT6 tumours of CXCR2-deficient mice contained very low levels of neutrophils prior to PDT treatment $(1.37 \pm 0.04 \%$ of total cells). HPPH-PDT raised these to $3.98 \pm 0.48 \%$ of total cells $(P<0.006)$. This compares to neutrophil levels of $4.10 \pm 0.83 \%$ of total cells in untreated tumours $v s$ $16.9 \pm 3.22 \%$ of total cells in HPPH-PDT-treated tumours $(P<0.018)$ in wild-type mice.

\section{REFERENCES}

Adams DH, Lloyd AR (1997) Chemokines: leucocyte recruitment and activation cytokines. Lancet 349: 490-495

Adili F, Statius van Eps RG, Karp SJ, Watkins MT, LaMuraglia GM (1996) Differential modulation of vascular endothelial and smooth muscle cell function by photodynamic therapy of extracellular matrix: novel insights into radical-mediated prevention of intimal hyperplasia. J Vasc Surg 23: $698-705$

Anderson DC, Mace ML, Brinkley BR, Martin RR, Smith CW (1981) Recurrent infection in glyocogenosis type Ib: abnormal neutrophil motility related to impaired redistribution of adhesion sites. J Infect Dis 143: $447-459$

Baumann H (1988) Electrophoretic analysis of acute phase plasma proteins. Methods Enzymol 163: 566-594

Baumann H, Gauldie J (1994) The acute phase response. Immunol Today 15: $74-80$

Baumann H, Prowse KR, Marinkovic S, Won K-A, Jahresis GP (1989) Stimulation of hepatic acute phase response by cytokines and glucocorticoids. Ann NY Acad Sci 557: 280-297

Bellnier DA, Henderson BW, Pandey RK, Potter WR, Dougherty TJ (1993) Murine pharmacokinetics and antitumor efficacy of the photodynamic sensitizer 2-[1-hexyloxyethyl]-2-devinyl pyropheophorbide-a. J Photochem Photobiol B 20: 55-61
These results combined indicate that PDT-enhanced neutrophil migration is dependent upon E-selectin and MIP-2, but is not influenced by IL-6. MIP-2 neutralisation has also been shown to reduce neutrophil recruitment in delayed type hypersensitivity responses (Biedermann et al, 2000).

In summary, we have shown that HPPH-PDT, like Photofrin ${ }^{\circledR}$ -PDT, initiates a local, albeit less severe, local inflammatory response. It is characterised by an influx of neutrophils into the treated tumour upon the presence of MIP-2 and E-selectin, which are induced locally in a temporal manner following PDT. Neutralisation of these MIP-2 and E-selectin eliminated neutrophil infiltration and increased adhesiveness to tumour microvasculature. Thus, HPPH-PDT-induced inflammation appears to be due, at least in part, to the coordinated induction of chemokine and adhesion molecule expression and activation, which results in the migration of neutrophils into the treated tumour. Once at the tumour site, neutrophils have been implicated in direct tumour cell kill, recruitment of leucocytes and lymphocytes through chemokine/cytokine secretion and tumour rejection in T-cell-dependent reactions (reviewed in Di Carlo et al, 2002). In addition, some studies have suggested that neutrophils can also promote malignant growth and progression (Pekarek et al, 1995). The results presented here begin to define the mechanisms behind PDT-induced neutrophil migration, which are critical to our understanding of the role these cells play in long-term tumour suppression by PDT. Furthermore, an understanding of the mechanisms leading to PDT-induced inflammation has the potential to provide a means of optimising clinical PDT, possibly through regulation of the mediators of the response. Studies are currently underway to determine whether the HPPH-PDT-induced inflammatory response is involved in the generation of antitumour immunity observed after HPPH-PDT.

\section{ACKNOWLEDGEMENTS}

This work was supported by NIH Grant PO1 CA55791 (BWH), The Roswell Park Alliance (SOG), NIH Grant RO1 DK33886 (HB), NIH Grant RO1 CA79765 (SSE), Department of Defense DAMD 17-8-8311 (SSE) and partially supported by shared resources of the Roswell Park Cancer Center support grant (P30 CA16056).
Biedermann T, Kneilling M, Mailhammer R, Maier K, Sander CA, Kollias G, Kunkel SL, Hültner L, Röcken M (2000) Mast cells control neutrophil recruitment during $\mathrm{T}$ cell-mediated delayed-type hypersensitivity reactions through tumor necrosis factor and macrophage inflammatory protein 2. J Exp Med 192: $1441-1451$

Bozic CR, Kolakowski LF, Gerard NP, Garcia-Rodriguez C, Von UexkullGuldenbanc C, Conklyn MJ, Breslow R, Showell HJ, Gerard C (1995) Expression and biologic characterization of the murine chemokine $\mathrm{KC}$. J Immunol 154: 6048-6057

Butcher EC, Picker LJ (1996) Lymphocyte homing and homeostasis. Science 272: $60-66$

Cecic I, Korbelik M (2002) Mediators of peripheral blood neutrophilia induced by photodynamic therapy of solid tumors. Cancer Lett 183: $43-51$

Dalrymple SA, Lucian LA, Slattery R, McNeil T, Aud DM, Fuchino S, Lee F, Murray R (1995) Interleukin-6-deficient mice are highly susceptible to Listeria monocytogenes infection: correlation with inefficient neutrophilia. Infect Immun 63: 2262-2268

Dellian M, Abels C, Kuhnle GE, Goetz AE (1995) Effects of photodynamic therapy on leucocyte-endothelium interaction: differences between normal and tumour tissue. $\mathrm{Br} J$ Cancer 72: $1125-1130$ 
de Vree WJ, Essers MC, De Bruijn HS, Star WM, Koster JF, Sluiter W (1996a) Evidence for an important role of neutrophils in the efficacy of photodynamic therapy in vivo. Cancer Res 56: 2908-2911

de Vree WJ, Fontijne-Dorsman AN, Koster JF, Sluiter W (1996b) Photodynamic treatment of human endothelial cells promotes the adherence of neutrophils in vitro. Br J Cancer 73: $1335-1340$

Di Carlo E, Forni G, Lollini P, Colombo MP, Modesti A, Musiani P (2002) The intriguing role of polymorphonuclear neutrophils in antitumor reactions. Blood 97: $339-345$

Dougherty TJ (2002) An update on photodynamic therapy applications. J Clin Laser Med Surg 20: 3-7

Dougherty TJ, Gomer CJ, Henderson BW, Jori G, Kessel D, Korbelik M, Moan J, Peng Q (1998) Photodynamic therapy. J Natl Cancer Inst 90: $889-905$

Evans S, Matthews W, Perry R, Fraker D, Norton J, Pass HI (1990) Effect of photodynamic therapy on tumor necrosis factor production by murine macrophages. I Natl Cancer Inst 82: 34-39

Evans SS, Wang WC, Bain MD, Burd R, Ostberg JR, Repasky EA (2001) Fever-range hyperthermia dynamically regulates lymphocyte delivery to high endothelial venules. Blood 97: 2727-2733

Gollnick SO, Liu X, Owczarczak B, Musser DA, Henderson BW (1997) Altered expression of interleukin 6 and interleukin 10 as a result of photodynamic therapy in vivo. Cancer Res 57: 3904-3909

Henderson BW, Bellnier DA, Greco WR, Sharma A, Pandey RK, Vaughan LA, Weishaupt KR, Dougherty TJ (1997) An in vivo quantitative structure - activity relationship for a congeneric series of pyropheophorbide derivatives as photosensitizers for photodynamic therapy. Cancer Res 57: 4000-4007

Henderson BW, Waldow SM, Mang TS, Potter WR, Malone PB, Dougherty TJ (1985) Tumor destruction and kinetics of tumor cell death in two experimental mouse tumors following photodynamic therapy. Cancer Res 45: $572-576$

Hurst SM, Wilkinson TS, McLoughlin RM, Jones S, Horiuchi S, Yamamoto N, Rose-John S, Fuller GM, Topley N, Jones SA (2001) IL-6 and its soluble receptor orchestrate a temporal switch in the pattern of leukocyte recruitment seen during acute inflammation. Immunity 14: 705-708

Kick G, Messer G, Goetz A, Plewig G, Kind P (1995) Photodynamic therapy induces expression of interleukin 6 by activation of AP-1 but not NF- $\kappa$ B DNA binding. Cancer Res 55: $2373-2379$

Knittel T, Fellmer P, Neubauer K, Kawakami M, Grundmann A, Ramadori G (1997) The complement-activating protease P100 is expressed by hepatocytes and is induced by IL-6 in vitro and during acute phase reaction in vivo. Lab Invest 77: $221-230$

Kopf M, Baumann H, Freer G, Freudenberg M, Lamers M, Kishimoto T, Zinkernagel R, Bluethmann H, Kohler G (1994) Impaired immune and acute-phase responses in interleukin-6-deficient mice. Nature 368: 339 342

Korbelik M (1996) Induction of tumor immunity by photodynamic therapy. J Clin Laser Med Surg 14: 329-334

Korbelik M, Cecic I (1998) Enhancement of tumour response to photodynamic therapy by adjuvant mycobacterium cell-wall treatment. J Photochem Photobiol B 44: $151-158$

Korbelik M, Cecic I (1999) Contribution of myeloid and lymphoid host cells to the curative outcome of mouse sarcoma treatment by photodynamic therapy. Cancer Lett 137: 91 - 98
Korbelik M, Krosl G, Krosl J, Dougherty GJ (1996) The role of host lymphoid populations in the response of mouse EMT6 tumor to photodynamic therapy. Cancer Res 56: 5647-5652

Kurt RA, Park JA, Panelli MC, Schluter SF, Marchalonis JJ, Carolus B, Akporiaye ET (1995) T lymphocytes infiltrating sites of tumor rejection and progression display identical $\mathrm{V} \beta$ usage but different cytotoxic activities. J Immunol 154: $3969-3974$

Lewinsohn DM, Bargatze RF, Butcher EC (1987) Leukocyte-endothelial cell recognition: evidence of a common molecular mechanism shared by neutrophils, lymphocytes, and other leukocytes. I Immunol 138: 4313 4321

Mackay CR (2001) Chemokines: immunology's high impact factors. Nature Immunol 2: $95-101$

Minta JO, Fung M, Turner S, Eren R, Zemach L, Rits M, Goldberger G (2000) Cloning and characterization of the promoter for the human complement facto I (C3b/C4b in activator) gene. Gene 208: 17-24

Nseyo UO, Whalen RK, Duncan MR, Berman B, Lundahl SL (1990) Urinary cytokines following photodynamic therapy for bladder cancer. Urology 36: $167-171$

Pekarek LS, Starr BA, Toledano AY, Schreiber H (1995) Inhibition of tumor growth by elimination of granulocytes. I Exp Med 181: 435-440

Rollins BJ (1997) Chemokines. Blood 90: 909-928

Romano M, Sironi M, Toniatti C, Polentarutti N, Fruscella P, Ghezzi P, Faggioni R, Luini W, van Hinsbergh V, Sozzani S, Bussolino F, Poli V, Ciliberto G, Mantovani A (1997) Role of IL-6 and its soluble receopton in induction of chemokines and leukocyte recruitment. Immunity 6: 315318

Rousset N, Vonarx V, Eléouet E, Carré J, Kerninon E, Lajat Y, Patrice T (1999) Effects of photodynamic therapy on adhesion molecules and metastasis. I Photochem Photobiol B 52: 65-73

Schieferdecker HL, Schlar G, Koleva M, Gotze O, Jungermann K (2000) Induction of functional anaphylatoxin C5a receptors on hepatocytes by in vivo treatment of rats with IL-6. J Immunol 164: $5453-5458$

Sluiter W, de Vree WJ, Pietersma A, Koster JF (1996) Prevention of late lumen loss after coronary angioplasty by photodynamic therapy: role of activated neutrophils. Mol Cell Biochem 157: 233-238

Smith CW, Marlin SD, Rothlein R, Toman C, Anderson DC (1989) Cooperative interactions of LFA-1 and Mac-1 with intercellular adhesion molecule- 1 in facilitating adherence and transendothelial migration of human neutrophils in vitro. J Clin Invest 83: 2008-2017

Suffredini AF, Fantuzzi G, Badolato R, Oppenheim JJ, O’Grady NP (1999) New insights into the biology of the acute phase response. J Clin Immunol 19: 203 - 214

Sun J, Cecic I, Parkins CS, Korbelik M (2002) Neutrophils as inflammatory and immune effectors in photodynamic therapy-treated mouse SCCVII tumours. Photochem Photobiol Sci 1: 690-695

Suwa T, Hogg JC, Klut ME, Hards J, van Eeden SF (2001) Interleukin-6 changes deformability of neutrophils and induces their sequestration in the lung. Am J Respir Crit Care Med 163: 970-976

Workman P, Twentyman P, Balkwill R, Balmain A, Chaplin S, Double J, Embleton J, Newell D, Raymond R, Stables J, Stephens T, Wallace J (1998) United Kingdom Co-ordinating committee on cancer research (UKCCCR) guidelines for the welfare of animals in experimental neoplasia (second edition). Br J Cancer 77: 1 - 10 